\title{
STRATEGI DIFERENSIASI PADA PT MATAHARI DEPARTMENT STORE TBK
}

\author{
Shieni \\ Program Studi Magister Manajemen Universitas Tarumanagara \\ xienichen@gmail.com
}

\begin{abstract}
The aim of this research is to explain the differentiation strategies of PT Matahari Department Store Tbk to attract customers. This will be done through a discussion and analysis of all five of the differentiation strategies which are; product, service, personnel, channel and image. The theoretical framework gives an overview of the differentiation strategies; it also provides the reader with a description of consumer decision process, competitive advantage, strategic customer and key competitors. The methodology chapter provides a description of the method choices for this research; this study is done by a qualitative approach. The analysis chapter provides the differentiations strategies that are mentioned in the theoretical framework. The conclusion will conclude the analysis of the theoretical parts of this thesis and answer the research question. The needed future improvements will be discussed closely in the suggestion.
\end{abstract}

Abstrak : Tujuan dari penelitian ini adalah untuk menjelaskan strategi diferensiasi PT Matahari Department Store Tbk untuk menarik pelanggan. Pada penelitian ini akan dilakukan melalui diskusi dan analisis dari lima strategi diferensiasi yaitu; produk, layanan, personel, saluran, dan citra. Kerangka teoritis memberikan gambaran tentang strategi diferensiasi; yang juga memberikan pembaca deskripsi dari proses pengambilan keputusan konsumen, keunggulan kompetitif, pelanggan strategis dan pesaing utama. Bab metodologi penelitian memberikan deskripsi tentang pilihan metode untuk penelitian ini; penelitian ini dilakukan dengan pendekatan kualitatif. Bab analisis menyediakan strategi diferensiasi yang disebutkan dalam kerangka teoritis. Kesimpulan akan menyimpulkan analisis bagian teoritis dari tesis ini dan menjawab pertanyaan penelitian. Perbaikan yang dibutuhkan di masa depan akan dibahas secara dekat dalam saran.

Keywords : Differentiation Strategies, Matahari, Fashion Industry, Attract Customer

\section{PENDAHULUAN}

Pemasaran adalah sebuah fungsi organisasi dan seperangkat proses untuk menciptakan, mengkomunikasikan, menyampaikan nilai kepada pelanggan dan untuk mengelola hubungan dengan pelanggan yang menguntungkan organisasi dan pemangku kepentingannya (Kotler dan Keller, 2012). Strategi diferensiasi berusaha menyediakan produk atau jasa yang menawarkan manfaat yang berbeda dari pesaing lainnya, yang dinilai oleh pembeli produk atau pengguna jasa (Johnson, Scholes, dan Whittington, 2008:70).

Fashion merupakan salah satu industri terbesar dengan tingkat persaingan tinggi yang mengharuskan perusahaan untuk membedakan dirinya dengan perusahaan fashion lain. Salah satu faktor yang menjadi semakin penting dalam industri fashion adalah merek produk. Salah satu perusahaan ritel lokal terbesar di Indonesia khususnya dalam bidang fashion adalah PT Matahari Department Store Tbk ("Matahari"). Matahari merupakan salah satu anak perusahaan dari Lippo Group, bergerak dalam usaha jaringan gerai serba ada yang menyediakan berbagai macam barang seperti pakaian, aksesoris, tas, sepatu, kosmetik, dan peralatan rumah tangga. Matahari telah mengukir sejarah panjang dalam dunia ritel Indonesia. 


\section{Pokok Masalah}

Berdasarkan latar belakang permasalahan yang telah dikemukakan sebelumnya, maka identifikasi masalah dalam penelitian ini adalah:

- Diferensiasi pemasaran apakah yang digunakan sebagai strategi oleh Matahari untuk membedakan dirinya dengan perusahaan lain?

- Apakah strategi diferensiasi pemasaran yang digunakan oleh Matahari itu sudah bisa menarik pelanggan?

\section{Tujuan Penelitian}

Tujuan dari penelitian ini adalah

- Mengkaji diferensiasi pemasaran yang digunakan sebagai strategi oleh Matahari untuk membedakan dirinya dengan perusahaan lain.

- Mengkaji apakah strategi diferensiasi pemasaran yang digunakan oleh Matahari itu sudah bisa menarik pelanggan.

\section{Ruang Lingkup Penelitian}

Adapun ruang lingkup penelitian ini adalah strategi diferensiasi yang digunakan Matahari, dan kajian apakah strategi diferensiasi pemasaran yang digunakan oleh Matahari itu sudah bisa menarik pelanggan.

\section{TELAAH KEPUSTAKAAN}

Pada dasarnya diferensiasi adalah tindakan merancang satu set perbedaaan yang berarti untuk membedakan penawaran perusahaan dari penawaran pesaing (Kotler, 1997). Diferensiasi dapat dilakukan melalui lima dimensi berikut ini, yaitu:

- Diferensiasi produk

- Diferensiasi pelayanan

- Diferensiasi personel

- Diferensiasi saluran

- Diferensiasi citra.

Diferensiasi produk adalah salah satu strategi perusahaan untuk membedakan produknya terhadap produk pesaing, untuk membuatnya lebih menarik bagi target pasar tertentu. Menurut Kotler dan Keller (2012), perusahaan memiliki banyak kemungkinan diferensiasi produk. Ketika produk tidak dapat dibedakan, menambahkan layanan bernilai, atau meningkatkan kualitas pelayanan dapat menjadi kunci keberhasilan keunggulan kompetitif (Kotler dan Keller, 2012). Diferensiasi saluran mengacu pada perusahaan yang dapat mencapai keunggulan kompetitif melalui cara sebuah perusahaan merancang saluran distribusinya. Diferensiasi saluran melihat bagaimana cara perusahaan mendistribusikan, menjual, atau menawarkan produknya kepada pelanggannya. Diferensiasi citra dapat diciptakan dari bagaimana perusahaan merancang tanda dan logo pada produknya. Simbol yang dipilih harus dikomunikasikan melalui iklan yang menyampaikan kepribadian perusahaan atau merek (Kotler, Wong, Saunders, dan Armstrong, 2005).

Menurut Michael Porter dalam Kotler dan Keller (2012), keunggulan kompetitif adalah kemampuan perusahaan untuk tampil dalam satu atau lebih banyak cara yang tidak bisa atau tidak cocok dengan pesaing. Pelanggan strategis adalah orang yang menjadi sasaran strategi utama. Mereka memiliki pengaruh paling besar terhadap barang atau jasa apa yang dibeli dan diminta, dan oleh karena itu mereka mewakili target audiens untuk pengembangan produk di perusahaan (Johnson, Scholes dan Whittington, 2008).

Tiga unsur dalam struktur proses komunikasi adalah pelaku komunikasi, material komunikasi dan proses komunikasi itu sendiri. Menurut Kotler (2000) ada dua unsur yang merupakan pihak-pihak utama dalam komunikasi yaitu pengirim (sender) dan penerima (receiver), dua unsur yang merupakan alat komunikasi utama yaitu pesan (message) dan 
media, empat unsur yang merupakan fungsi komunikasi utama yaitu pengkodean (encoding), penguraian kode (decoding), tanggapan (response), dan umpan balik (feedback). Unsur terakhir dalam sistem tersebut adalah gangguan (noise).

Ketika konsumen membeli sesuatu, terdapat lima langkah atau lima proses yang digunakan untuk memahami bagaimana konsumen membuat keputusan. Kelima langkah atau lima proses yang digunakan untuk memahami bagaimana konsumen membuat keputusan menurut Kotler dan Keller (2012) adalah sebagai berikut:

- Pengenalan masalah (problem recognition

- Pencarian informasi (information search

- Evaluasi alternatif (evaluation of alternatives

- Pembelian (purchase

- Evaluasi pasca pembelian (post-purchase behavior).

\section{GAMBARAN UMUM}

PT Matahari Department Store Tbk ("Matahari") adalah department store pilihan Indonesia yang menawarkan produk-produk fashion terkini dan berkualitas tinggi, serta pengalaman berbelanja yang menyenangkan. Matahari hingga kini telah mengoperasikan jaringan department store terbesar di Indonesia. Pada 31 Desember2017, Matahari memiliki 155 gerai di 73 kota di seluruh Indonesia, mencakup 980.031 meter persegi dari total ruang ritel, dan satu toko online, yaitu MatahariStore.com.

Visi Matahari adalah semua orang Indonesia dapat tampil menarik dan nyaman. Misi Matahari yaitu menyediakan berbagai kebutuhan fashion berkualitas dan terjangkau bagi para pelanggan dengan suasana yang ramah, sehingga dapat memberikan pengalaman belanja yang menyenangkan dan meningkatkan kualitas hidup secara keseluruhan.

\section{METODOLOGI PENELITIAN}

Jenis penelitian yang dilakukan adalah penelitian bisnis kualitatif, sedangkan periode penilitian yang digunakan dalam pembahasan data sekunder adalah laporan keuangan Matahari tahun 2017 dan 2016. Pendekatan deduktif, yaitu pemaparan hal yang bersifat umum kemudian menyebarkan ke hal khusus digunakan dalam penelitian kualitatif, yang berarti teori-teori yang digunakan nantinya mengarahkan kepada penelitian. Dalam penyusunan tesis ini, data yang digunakan adalah data primer dan sekunder. Metode analisis yang digunakan dalan penelitian ini dilakukan dengan melakukan business analysis. Menurut Kotler dan Keller (2012:583), setelah perusahaan mengembangkan konsep produk dan strategi pemasaran, perusahaan kemudian dapat mengevaluasi daya tarik bisnis perusahaan terhadap pelanggan. Perlu dipersiapkan angka penjualan, biaya, dan laba untuk menentukan apakah angka tersebut memenuhi tujuan perusahaan.

\section{ANALISIS DAN BAHASAN TEMUAN}

Strategi diferensiasi yang digunakan oleh Matahari sehingga dapat membedakan dirinya dengan perusahaan lain adalah diferensiasi produk dengan menciptakan private label direct purchase nya sendiri dengan berbagai brand seperti Nevada, Connexion, St Yves, Little M dan Cole, pembukaan gerai Nevada sebagai private label, inisiatif merchandising baru: produk Disney, inisiatif merchandising baru: produk Naura-Neona, bekerja sama dengan Indonesian Fashion Forward (IFF), dan inisiatif merchandising baru: produk Raffi Ahmad RA JEANS. Diferensiasi pelayanan dengan menciptakan budaya perbaikan, karyawan pada gerai yang mengenakan seragam, kesempatan konsumen menukarkan produk, Matahari Rewards, operasi logistik yang terdepan di pasar, meningkatkan fokus pada layanan pelanggan, dan penilaian pelayanan oleh pihak ketiga independen. Diferensiasi personel dengan memprioritaskan kualitas dan pengembangan karyawannya. Diferensiasi saluran dengan memiliki jaringan nasional gerai terbesar, operasional gerai yang optimal, melakukan 
ekspansi gerai baru, desain gerai yang menarik, peningkatan berkelanjutan atas gerai, dan mengadakan operasi online. Diferensiasi citra yang dilihat dari bagaimana perusahaan merancang tanda dan logo pada produknya, serta kekuatan citra Matahari yang telah menghasilkan banyak penghargaan selama beberapa tahun.

Analisa bisnis pada laporan keuangan Matahari menunjukkan bahwa Matahari sudah bisa menarik pelanggan, yaitu berdasarkan pendapatan bersih yang meningkat $\mathrm{Rp}$ 126,8 miliar

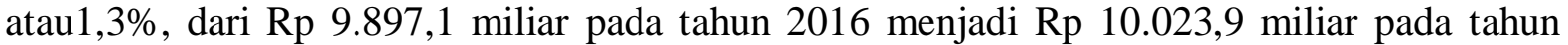
2017. Beban pokok pendapatan meningkat Rp 76,7 miliar,atau 2,1\%, dari Rp 3.685,3 miliar pada tahun 2016 menjadi Rp 3.762,0 miliar, di mana hal ini disebabkan oleh adanya kenaikan penjualan ritel. Namun, Laba Perseroan Sebelum Pajak Penghasilan menurun Rp 136,5 miliar atau 5,4\% dari Rp 2.532,7 miliar pada tahun 2016 menjadi Rp 2.396,2 pada tahun 2017 karena meningkatnya beban usaha. Dengan meningkatnya beban usaha, maka Laba Bersih Perseroan menurun Rp 112,6 miliar. Rasio profitabilitas seperti profit margin, asset turnover, return on asset, return on ordinary shareholder's equity mengalami penurunan, yang didominasi oleh menurunnya pendapatan bersih, laba bersih, kenaikan aset yang berasal dari Aset Tidak Lancar Lainnya sebagai akibat dari penambahan investasi pada PT Global Ecommerce Indonesia sebesar Rp 590 miliar, dan meningkatnya rata-rata nilai ekuitas pemegang saham. Nilai rasio price earning meningkat di tahun 2017 dikarenakan harga market price yang tidak mengalami perubahan, sedangkan harga earning per share mengalami penurunan dikarenakan terjadinya penurunan angka laba bersih.

\section{SARAN}

Saran untuk penelitian selanjutnya adalah:

- Penelitian selanjutnya dapat dilakukan analisis dan wawancara lebih mendalam agar semakin terllihat strategi yang digunakan oleh Matahari untuk membedakan dirinya dengan perusahaan lain.

- Penelitian selanjutnya dapat dilakukan analisis dan metode lain dalam mengevaluasi apakah strategi diferensiasi Matahari sudah dapat menarik pelanggan, baik ditinjau dari laporan keuangan, maupun industri sejenis.

\section{DAFTAR PUSTAKA}

Armstrong, G., Kotler, P. (2010). Principles of marketing, thirteenth edition. Pearson Education, Upper Saddle River

Bruhn, M., Georgi, D. (2006). Services marketing: managing the service value chain, Pearson Education, Harlow

Bryman, A., and Bell, E. (2007). Business research methods, second edition. Oxford University Press

David, Fred R., David, Forest R. (2015). Strategic Management: A Competitive Advantage Approach, Concepts \& Cases, $15^{\text {th }}$ Edition. Pearson Education Inc

Dwivedi, D. N. (2006). Microeconomics: Theory And Applications. Dorling Kindersley: Pearson Education, Delhi, India

Fontana, A., Prokos, A.H. (2007). The interview: from formal to postmodern. Left Coast Press, California 
Hines, T., Bruce, M. (2007). Fashion marketing: contemporary issues second edition. Oxford: Butterworth-Heinemann

Hitt, A.M., Ireland, R.D., Hoskisson, R.E. (2009). Strategic management: competitiveness and globalization: concepts \& cases eighth edition. Cengage Learning Inc., Canada

Hoyle, D. (2005). Automotive quality systems handbook. incorporating ISO/TS 16949:2002 second edition

Johnson, G., Sholes, K., Whittington, R. (2008). Exploring Corporate Strategy (Eighth Edition). England: Pearson Education Prentice Hall

Kotler, Philip. (1973). Atmospherics as a marketing tool. Journal of retailing, Volume 49, $\mathrm{Nr}$ 4, pp. 48-64

Kotler, Philip. (1997). Marketing Management “Analysis, Planning, Implementationand Control” (9th ed.). New Jersey: Prentice Hall International, Inc.

Kotler, Philip.(2000). Marketing Management (The Millennium Edition). New Jersey: Prentice Hall Intl, Inc

Kotler, Philip, and Keller, Kevin Lane. (2007). A framework for marketing management, third edition. Pearson Education

Kotler, Philip and Keller, Kevin Lane. (2012). Marketing Management (14th edition). Pearson Education Prentice Hall

Kotler P., Wong V., Saunders J., Armstrong G. (2005). Principles of Marketing (Fourth European Edition). England: Pearson Education Prentice Hall

Lamb, C.W., Hair, J.F., McDaniel, C. (2009).Essentials of Marketing, sixth edition, Neil Marquardt, Mason

Moore, M., Fairhurst, A. (2003). Marketing capabilities and firm performance in fashion retailing, Journal of fashion marketing and management, vol. 7, no 4. ss. 386-397.

Nargundkar, R. (2006). Services Marketing, second edition, Tata McGraw-Hill publishing company, New Delhi

Stahlberg, M. \& Maila, V. (2009). Shopper marketing: how to increase purchase decisions at the point of sale. Kogan Page Ltd

Solomon, M. \& Bamossy, G. (2007) Consumer behaviour: An European perspective. Third edition. Pearson education limited

www.matahari.co.id

www.wikipedia.org 
